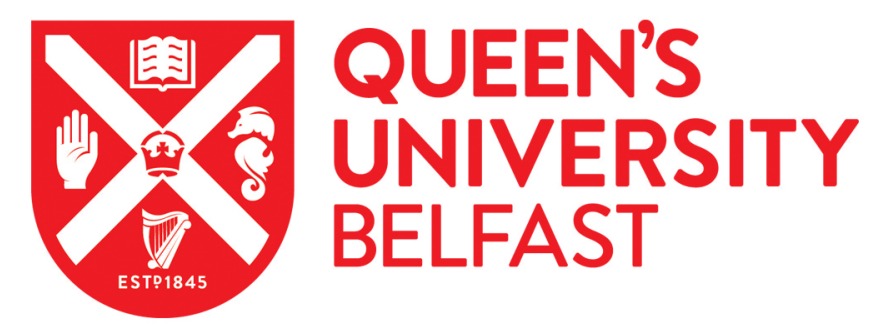

\title{
Rigidity in routines and the development of resistance to change in individuals with Prader-Willi syndrome
}

Haig, E. L., \& Woodcock, K. A. (2017). Rigidity in routines and the development of resistance to change in individuals with Prader-Willi syndrome. Journal of intellectual disability research : JIDR, 61(5), 488-500. https://doi.org/10.1111/jir.12368

Published in:

Journal of intellectual disability research : JIDR

Document Version:

Peer reviewed version

Queen's University Belfast - Research Portal:

Link to publication record in Queen's University Belfast Research Portal

Publisher rights

(C) 2017 John Wiley \& Sons Ltd. This work is made available online in accordance with the publisher's policies. Please refer to any applicable terms of use of the publisher.

\section{General rights}

Copyright for the publications made accessible via the Queen's University Belfast Research Portal is retained by the author(s) and / or other copyright owners and it is a condition of accessing these publications that users recognise and abide by the legal requirements associated with these rights.

Take down policy

The Research Portal is Queen's institutional repository that provides access to Queen's research output. Every effort has been made to ensure that content in the Research Portal does not infringe any person's rights, or applicable UK laws. If you discover content in the Research Portal that you believe breaches copyright or violates any law, please contact openaccess@qub.ac.uk. 
This manuscript was accepted for publication in the Journal of Intellectual Disability Research on $1^{\text {st }}$ February 2017.

Rigidity in routines and the development of resistance to change in individuals with Prader-Willi syndrome

\section{Running head}

Environmental rigidity and developing resistance to change

Key words

behavioural flexibility;

insistence on sameness;

autism spectrum disorder;

Prader-Willi syndrome;

challenging behaviour;

task switching 


\section{Background}

Individuals with Prader-Willi syndrome (PWS) commonly show debilitating resistance to change, which has been linked to cognitive deficits in task switching. Anecdotal reports suggest that exposure to flexibility in routines during development may be beneficial for limiting subsequent resistance to change in people with PWS; which is consistent with a beneficial role of such exposure on the development of task switching, highlighted in typical children. Here we aim to investigate the development of resistance to change in individuals with PWS and hypothesise that exposure to increased rigidity in routines will be associated with increased subsequent resistance to change.

\section{Method}

An author compiled informant report interview and two previously validated questionnaires were administered to the caregivers of 10 individuals with PWS (5-23 years). The interview examined rigidity in routines and resistance to change across life stages defined by easily distinguishable events (before school; during primary school; during secondary school; after school; currently), using open ended and structured yes/no and fivepoint Likert questions. Open ended data were coded using an author compiled system. Responses from two additional informants; and data from the questionnaires were used to assess inter-informant reliability and concurrent validity of the structured questions.

\section{Results}

The validity of the interview was supported by acceptable inter-rater reliability of the open ended coding system; and inter-informant reliability, internal consistency and concurrent validity of structured questions. Descriptive analyses of ratings of behaviour change showed a pattern of increasing resistance to change over the life course for the four oldest individuals, who had all been exposed to substantial rigidity in routines before and during primary school. Furthermore, only one individual - currently in primary school - was exposed to very little rigidity in routines before and during primary school, and he had showed a decrease in resistance to change after entering primary school. Open ended data showed that more individuals currently evidencing little resistance to change had been exposed to parent or self-imposed flexibility in routines, than those currently evidencing substantial resistance to change. However, correlational analyses on rigidity and resistance to change ratings, highlighted the possibility that rigidity during primary school is most relevant for developing resistance to change. Finally, open ended data emphasised an important beneficial role of rigidity in routines for limiting the current challenging behaviour of individuals with high resistance to change.

\section{Conclusion}

Since task switching appears to evidence a period of high developmental sensitivity during early primary school years, we propose that this period may represent a critical time when increasing flexibility in the routines of children with PWS could limit the development of resistance to change. However, a careful balance would need to be struck, given the apparent benefit of rigid routines on current behaviour. Further work in this area is much needed. 


\section{Introduction}

Prader-Willi Syndrome (PWS) is a neurodevelopmental disorder caused by absence of genetic information on the paternal copy of chromosome 15 (q11-q13), estimated to be shown by at least 1:52,000 individuals in the UK (Cassidy, 1997; Whittington et al., 2001; Boer et al., 2002). PWS is associated with mild to moderate intellectual disability (e.g. Whittington et al., 2004). The behavioural phenotype - behaviour shown more commonly in individuals with PWS than in those without, Dykens et al., 1995 - includes strong resistance to change and frequent temper outbursts, a substantial proportion of which follow changes to routines or expectations (Holland et al., 2003; Moss et al., 2009; Tunnicliffe et al., 2014; Woodcock et al., 2009a). Temper outbursts represent one of the most impairing aspects of PWS (Manning et al., 2016; Shivers, Leonczyk \& Dykens, et al., 2016).

\section{Executive functioning, task switching and resistance to change in individuals with PWS}

Executive functions are complex cognitive processes that monitor and regulate cognition and behaviour, particularly in novel and complex situations (Collette et al., 2005). Individuals with PWS show deficits in executive function, particularly in task switching (Chevalère et al., 2013; 2015; Copet et al., 2010; Hutchison et al., 2015; Jauregi et al., 2007; Woodcock et al., 2009b; Woodcock et al., 2010). Task switching is the ability to switch mental processes so as to deal appropriately with environmental demands (Monsell, 2003). Task switching that is internally directed (not driven by explicit instruction) may be particularly impaired in individuals with PWS (Chevalère et al., 2015).

Importantly, deficits in task switching are associated with resistance to change in individuals with PWS (Woodcock et al., 2009b). It has been suggested that changes to expectations act as potent triggers for temper outbursts via an aversive state elicited by change-induced demands on deficient task switching (Woodcock et al., 2009c). Indeed, increased arousal and temper outburst behaviours can be precipitated by imposed changes to routines or expectations; or cognitive demands on task switching (Woodcock et al., 2011). Further, signalling changes in a predictable way - in other words reducing the unpredictability of changes - can reduce the temper outburst behaviours that ensue following changes (Bull et al., 2016).

There is growing evidence pointing towards such an association between deficits in switching and resistance to change in individuals with other neurodevelopmental disorders, for example autism spectrum disorder (Miller et al., 2012; Uddin et al., 2015), which may also be linked to specific deficits in internally directed task switching (Van Eylen et al., 2011).

\section{The typical development of switching and flexibility in routines}

Children around 6 years of age, who typically move from failing to passing simple rule switching paradigms, are more likely to pass if they have the capacity to represent rules in an abstract way (Kharitonova et al., 2009; Kharitonova \& Munakata, 2011). Children are likely to have more practice in representing rules in an abstract way if they are exposed to a range of varied contexts (flexible routines/environments), in which functioning would benefit from such abstract representations. This assertion is supported by the fact that neural connections representing abstract relations are engaged by paradigms that present tasks in a range of varied contexts (Cole et al., 2013). Indeed, children exposed to more unstructured activities around 6 to 7 years of age, appear to evidence better internally directed task switching (Barker et al., 2014; 2015). 
Flexibility versus rigidity in routines and resistance to change in individuals with PWS

Anecdotal reports have suggested that individuals with PWS exposed to more flexibility in routines during development - for example because their family has never had strict routines - are often those who evidence less resistance to change (Woodcock et al., 2009a; Woodcock et al., 2011). Further, in experimentally controlled settings, higher physiological arousal and more frequent temper outburst behaviours were evidenced following changes to previously novel routines, which participants with PWS had been exposed to over a longer compared to a shorter duration (Bull et al., 2015).

\section{Aims and hypotheses}

Thus, flexibility in environments during typical development may facilitate the progression of task switching; which plays an important role in resistance to change shown by individuals with PWS. Further, resistance to change may be reduced in individuals with PWS who have been exposed to less rigid routines.

Here we aim to investigate the natural development of resistance to change in individuals with PWS with respect to ongoing exposure to flexibility versus rigidity in routines. In this first pilot study in the area we employ a novel parent report interview method to examine resistance to change and routine rigidity across the lifespan. We hypothesise that participants who have been exposed to less rigidity in routines during their development, will evidence less current resistance to change.

\section{Participants}

\section{Methods}

The parents of three females and seven males with PWS, aged between 5 years 2 months and 23 years 7 months $(M=10$ years, $S D=6.26)$ participated. For inclusion, participants must have already started primary school. Six participants were still at primary school, three were at secondary school, and one was post school age. Caregivers were recruited via organisations supporting the needs of families with PWS in the United Kingdom and the United States. All parents provided written informed consent and the study was approved by [withheld for blind review].

\section{Measures}

\section{Informant Report Interview}

An author-compiled informant report interview was designed to provide structured and open ended information on participants' resistance to change and rigidity in routines over the life course. The initial interview schedule was piloted with the caregivers of two individuals with a neurodevelopmental disorder. Recordings of these interviews were examined by the research team and amendments made to the schedule to maximise face validity.

The interview was then administered to the parents of participants (henceforth, informants). The interview schedule included three leading open ended questions on participants' responses to change and rigidity in routines. The rest of the schedule was divided into five sections referring to different stages of the participants' lives (described with reference to specific events to aid recall, such as before primary school - from 4/5 years - and during secondary school - from $11 / 12$ to at least 16 years). Each section included yes/no; five-point Likert type rating; and open ended questions (see Table 1). 
Questions corresponded exactly across stages except for slight differences necessary for the questions relevant to the person's current behaviour. Additional open ended questions asked about key transitions (see supplementary materials for a full schedule). Respondents only answered questions on life stages that participants had already completed.

[Table1]

\section{Informant Report Questionnaires}

Two informant report questionnaire measures on repetitive behaviour allowed examination of the concurrent validity of the new interview. The Repetitive Behaviour Questionnaire (RBQ; Moss \& Oliver, 2008) describes 19 observable behaviours rated for frequency on a 5-point Likert type scale (never, once a month, once a week, once a day, more than once a day). The RBQ has been previously validated in a sample which included individuals with PWS, showing good inter-rater and test-re-test reliability, content validity and concurrent validity with the Autism Screening Questionnaire (Moss et al., 2009). The Childhood Routines Inventory (CRI; Evans et al., 1997) also involves the rating of nineteen observable behaviours for frequency on a five point Likert-type scale (never, a little, sometimes, quite a lot, and very much). Acceptable internal consistency for the CRI including two sub-scales, has been has been demonstrated in typical children (Evans et al., 1997). The CRI has also been used in populations with PWS (Greaves, Prince, Evans \& Charman, 2006; Woodcock et al., 2009; Wrigen \& Hansen, 2003).

\section{Procedure}

Interviews were conducted over Skype where acceptable for participants $(n=8)$, or telephone. Skype interviews were audio recorded, while telephone interviews were summarised in note form by a researcher. Open ended questions were presented first to minimise risk of interviewer bias on participants' open ended responses. Structured questions were presented next, with the aid of diagrams of the rating options emailed to participants in advance. Interviews lasted between forty minutes and two hours. The questionnaires were administered verbally after the interview (except one subsequently completed via email due to participant time constraints), to ensure questionnaires did not influence responses to the interview. Two further interviews were conducted with additional family members of two participants ( $20 \%$ of the sample) to assess inter-informant reliability.

\section{Coding of open ended information}

One researcher listened to/read all of the interviews and condensed the descriptive information into a set of operationally defined codes relevant to rigidity/flexibility in routines and/or resistance to change (see Table 2). To assess inter-informant reliability for the coding system, 17 clips from the interviews were transcribed (approximately two to four sentences in length) where one of the eight codes was deemed to be present by the first researcher (this amounted to $34.7 \%$ of the total instances where the codes were deemed present). The transcripts were independently read and categorised according to the operational definitions by another researcher. The researchers agreed on 15 out of the 17 clips, suggesting substantial agreement $(\mathrm{k}=.82 ; p<.001$; Vierra \& Garrett, 2005).

[Table 2] 


\section{Analysis}

\section{Assessing the validity of the interview schedule}

Analyses were conducted using IBM SPSS Statistics version 21. The internal consistency of the interview schedule was examined using a Kuder-Richardson 20 analysis (Clark \& Watson, 1995) to compare reports of participants reacting negatively to change in the open ended section (Table 1, Question 3) with the yes/no item on current upset following change (Table 1, Question 2).

Inter-informant reliability was assessed by establishing levels of agreement between pairs of informants who were interviewed about the same participant. A difference of one rating point was deemed reasonable to convey agreement because factors such as amount of time spent with the child, can be expected to influence informants' ratings (Hastings, 2002). Since, disagreement was rare, Cohen's Kappa was inappropriate, and percentage agreement was judged the most appropriate measure of reliability (McHugh, 2012; Vierra \& Garrett, 2005).

Concurrent validity was assessed between informants' interview responses on participants" current resistance to change and "insistence on routine" and "preference for the same household schedule" items on the RBQ and CRI respectively. These items are comprised in the RBQ insistence on sameness; and CRI repetitive behaviour subscales, scores on which were also examined since these represent broader constructs that comprise resistance to change. Spearman's rho correlations were conducted as appropriate given the ordinal data (Cohen \& Cohen, 1983).

\section{Assessing the relationship between rigidity in routines and resistance to change}

To examine the relationship between open ended reports and participants' resistance to change, the sample was split into two groups who evidenced a clinical difference in current resistance to change (Table 1, Question 5a). Individuals for whom change was rated as at least moderately difficult to deal with (rating of 3-5) were categorised as having high resistance to change; whilst this resistance was classified as low for individuals where the difficulty was at most mild (rating of 1-2). The percentages of reports of open ended codes within each group were calculated. The small group sizes meant that Fisher's Exact Test and Phi Statistic were most appropriate to assess statistical differences in proportions of the presence of the codes between the high and low resistance to change groups (McHugh, 2013). The Phi statistic is a correlation coefficient and as such, provides a measure of effect size within the range of 0 to 1 . Odds ratios were also computed since these provide a measure of effect size that is easier to conceptualise.

For rating questions, mean rigidity in routines across the five categories of routines examined (morning; mealtimes; bedtime; leisure/school/work; other) were calculated to index overall rigidity in routines at each life stage. Since the link between task switching development and exposure to flexible environments has been demonstrated in typical 6 to 7 year olds (Barker et al., 2014; 2015), we were interested in examining the relationship between rigidity in routines during each of the pre-school, and primary school periods; and current resistance to change. However, six participants were currently still at primary school, so their current behaviour corresponded to the during primary school period. Thus, alongside conducting a Spearman's rho correlation to examine current resistance to change in relation to rigidity in routines during the pre-school period, two additional corresponding correlations were conducted for rigidity during primary school (using current rigidity data 
from the six participants in primary school); and current rigidity (using current rigidity data from all participants). Further, a Spearman's partial correlation was conducted between rigidity during primary school and current resistance to change, controlling for current rigidity. Thus, an association between increased rigidity in routines during primary school and subsequent resistance to change would be supported if the relationship were stronger for rigidity during primary school than for current rigidity; and remained strong even controlling for current rigidity. Given the directional hypothesis and small sample size, onetailed $\mathrm{p}$-values were calculated.

\section{Results}

\section{Validity of the informant report interview Internal consistency}

All but one participant provided consistent information in the open ended and structured sections of the interview on participants' current resistance to change (KR-20 coefficient: .78; acceptable internal consistency; Clark \& Watson, 1995). One participant rated their child as not becoming upset following change, however, then proceeded to give an example of a time when their child did become upset following change.

\section{Inter-informant reliability}

Percentage agreement across the two informants was above $70 \%$ for all three types of rating question, which is considered acceptable (Salkind, 2010; De Los Reyes et al., 2011).

[Table 3]

\section{Concurrent validity}

Interview reported current resistance to change evidenced only a weak positive relationship with $\mathrm{RBQ}$ insistence on routine item $(r(8)=.21, p=.56)$; but a very strong positive relationship with the $\mathrm{CRI}$ prefers the same household routine or schedule every day $(r(8)=.85, p=.002)$. Further, while the relationship with the RBQ insistence on sameness subscale was weak $(r(8)=.16 ; p=.67)$, that with the CRI repetitive behaviour subscale was moderate $(r(8)=.42, p=.23)$. Where measures are designed to index exactly the same construct, correlations must be a strong as possible to demonstrate concurrent validity (Kline, 2013). However, here whilst the questionnaire measures were designed to tap repetitive behaviour, of which a preference for routine is one type; the author compiled interview was designed to tap a (challenging) behavioural response to routine change. Thus, the strong item level and moderate subscale level agreement between the CRI and author compiled interview provide support for its validity. However, the relationships between the RBQ and the interview do not add to this support.

\section{The relationship between rigidity in routines and resistance to change Individual profiles of development of resistance to change and rigidity in routines}

Descriptive analyses of developmental profiles at an individual level suggested that for the four older participants, resistance to change appeared to have increased over the life course in terms of becoming more difficult to deal, and longer; whilst rigidity in routines remained moderate to high before and during primary school (supplementary materials, Tables S1, S3 \& S4). Only one participant (male, 11 years; supplementary materials pp10) 
was classified as being exposed to consistently low rigidity - with mean rigidity ratings less than between rarely and sometimes having the same routine - and this child was reported to have shown less resistance to change during primary school than before school.

\section{Open ended data}

In relation to $(n=6)$ participants classified as currently demonstrating high resistance to change, more parents of those classified as showing low resistance to change $(n=4)$ reported making deliberate changes; not instigating routines; and that their child instigated some degree of flexibility. Conversely, more parents of participants classified as currently demonstrating high resistance to change, reported that the participant's behaviour was improved by implementing more routines (Table 4). All of these effects were medium to large in size (although did not attain statistical significance).

Almost all informants (in both groups) reported that participants react negatively to change. Further, around half of all informants (small difference across groups) reported that rigid routines were detrimental to participants' behaviour; response to change was affected by the context; and more routines were needed in early infancy.

[Table 4]

\section{Correlational analyses}

Current resistance to change was only weakly positively correlated with level of rigidity in routines before participants started school $(r(8)=.199, p=.290)$. This finding does not provide statistical support for the hypothesis that increased rigidity in routines at any stage during childhood would be associated with increased subsequent resistance to change. However, current resistance to change was strongly and significantly positively correlated with level of rigidity in routines during primary school $(r(8)=.692, p=.013)$; but only weakly positively correlated with current level of rigidity in routines $(r(8)=.263, p$ $=.231$ ). Indeed, even controlling for current rigidity using partial correlation, rigidity in routines during primary school predicted $47 \%$ of the variance in current resistance to change $(r(7)=.688, p=.20$; see Figure $S 1$ in supplementary materials). These findings provide some support the hypothesis that increased exposure to rigidity in routines would be associated with increased subsequent resistance to change. But further suggest that exposure to rigidity over a specific developmental period - that is presently encompassed by the "during primary school" life stage - may be most important.

\section{Discussion}

The author compiled informant interview - developed to examine rigidity in routines and resistance to change across the lifespan of individuals with PWS - evidenced acceptable internal consistency, inter-informant reliability and concurrent validity with the previously validated CRI questionnaire (although not with the RBQ). Individual profiles of reported change over time pointed towards increasing resistance to change over the life course in the participants who were already in secondary school or older, all of whom had been exposed to substantial rigidity in routines before and during primary school. Open ended information was consistent with children who currently evidenced relatively little resistance to change, having been exposed to more flexibility in routines during their development to date. 
However, these data also highlighted a beneficial effect of rigid routines for individuals with relatively high resistance to change, in terms of minimising current challenging behaviours. Correlational analyses highlighted the possibility that rigidity in routines specifically during primary school may be particularly relevant for subsequent resistance to change.

\section{Validity of the interview}

With respect to the interview, the present design assessed internal consistency, interrater reliability of the coding system for open ended information, inter-informant reliability, and concurrent validity of ratings on current resistance to change with respect to previously validated questionnaires. Most of these assessments converged to support the validity of the interview. However, contrary to expectation, insistence on routine (or its subscale) as reported on the RBQ (Moss et al., 2009), was only weakly positively associated with current resistance to change reported in the interview. This is surprising given the strong corresponding relationship with prefers the same household schedule or routine every day on the CRI (Evans et al., 1997). One possible explanation for this result comes from the differing rating systems employed in the RBQ and CRI. Whilst the CRI uses a subjective rating system (never to very much), which is similar to the presently employed interview rating system, based on ease of dealing with changes (easy to very difficult); the RBQ uses an objective frequency based rating system (never to more than once a day). Thus, it may be that participants' subjective biases had differing effects across the interview and CRI versus the RBQ ratings. Other measures that assess resistance to change and have been validated in populations of individuals with neurodevelopmental disorders - although not with PWS - are available and will be important to add to future research in this area (Green et al., 2006; Leekam et al., 2007; 2011; Wing et al., 2002).

\section{A sensitive period for the development of task switching when exposure to rigidity versus flexibility in routines is particularly important for limiting resistance to change?}

The descriptive and open ended data suggesting that increased rigidity in routines before and during primary school may be associated with later increased resistance to change, is consistent with our hypothesis. However, it is important to acknowledge that these data are descriptive (where statistical comparisons were possible using sub-groups, group sizes were too small for even large effects observed to be deemed significant). The correlational analyses, on the other hand, highlighted the possibility of a greater role of rigidity during primary school years (more so than the pre-school period), in subsequent resistance to change. An important part of the theoretical basis for the present hypothesis was the idea that the development of task switching can be influenced by experienced rigidity versus flexibility; and is linked to the development of resistance to change in individuals with PWS (Barker et al., 2014; 2015; Cole et al., 2013; Kharitonova et al., 2009; Kharitonova \& Munakata, 2011; Woodcock et al., 2009b; Woodcock et al., 2011). Considering the present findings, it is thus interesting to note that the ability to switch between two simple rules - a common requirement in switching measures showing deficits linked to PWS - typically emerges only around the age of 4 years and evidences improvements up until at least 11 years (Garon et al., 2008; Karbach \& Unger, 2014). Further, particularly rapid development in switching appears to occur around 6 years (Best et al., 2010; Kharitonova et al., 2009). Thus, there appears to be a period of developmental sensitivity during the primary school years when task switching is highly malleable, perhaps particularly for children who evidence relative deficiencies in these sorts of high level 
cognitive skills (Diamond \& Lee, 2011). Indeed, children of this age appear to be particularly susceptible to improvements in task switching via targeted training (Kronbach \& Kray, 2009); as they are susceptible to cognitive benefits from exposure to flexibility in daily activities (Barker et al., 2014; 2015).

Thus, we propose that increased flexibility in children's routines during the primary school years - perhaps particularly around the developmental age corresponding with early to mid-primary school - can facilitate the development of task switching in individuals with PWS, and so limit the development of resistance to change and associated temper outbursts. We note however, that the correlational nature of our data, alongside the potentially confounding impact of maturational change in resistance to change linked to a presently unmeasured variable - such as children or parents' genetic predispositions mean that this proposal remains just that. Future longitudinal and interventional research is much needed to examine this possibility further.

\section{A general effect of rigidity versus flexibility in routines on the development of resistance to change?}

It is also worth considering a potentially more general effect of rigidity in routines throughout development, on subsequent resistance to change. Forty percent of the present informants reported that participants needed more routines during early infancy. Given the developmental changes in the PWS behavioural phenotype - particularly with respect to early failure to thrive; and eating behaviour (Festen et al., 2008) - routines in early infancy might be particularly important. Thus, if the present informants based their ratings for rigidity during the pre-school period primarily on early infancy, the relatively small association between these ratings and current resistance to change, could represent an anomalous result. And in fact, rigidity in routines after early infancy but before school may be more associated with subsequent development of resistance to change. Long term longitudinal studies would be highly beneficial in unpicking these possibilities.

\section{The dilemma of a short term benefit versus a long term cost of rigid routines}

Present open ended reports support the notion that once individuals have developed a resistance to change, exposure to change can elicit upset and temper outbursts. This is consistent with the previous evidence that unexpected changes commonly trigger temper outbursts in individuals with PWS (Woodcock et al., 2009a; Woodcock et al., 2011; Tunnicliffe et al., 2014); and that making changes more predictable can reduce temper outburst behaviours (Bull et al., 2016). Thus, avoiding changes by increasing the rigidity of routines has an immediate beneficial effect of decreasing individuals' exposure to known triggers of negative emotion and temper outbursts. Further, rigid routines around food appear to facilitate diet management and therefore have added health benefits for individuals with PWS (Miller et al., 2013).

Overall however, the present findings point towards a long term cost of rigidity in routines on the development of resistance to change; and would thus support approaches seeking to increase the flexibility in routines that children are exposed to. Such approaches would be contrary to the current view on best practice (e.g. Mesibov \& Shea, 2008), presenting an important dilemma. Here, we propose a particularly important role for flexibility in routines during primary school years. Thus, one way to limit the dilemma may be to focus attention on this period. Ultimately though, the dilemma can only be reconciled by working out how to correctly balance children's exposure to flexibility and rigidity in 
routines so that the benefits of exposure to flexibility can be ascertained whilst still limiting the cost of that flexibility on children's immediate wellbeing; and this will be an important goal of future research.

\section{Limitations}

It is important to acknowledge, that the actions taken here to assess interview validity - whilst comprising a range of validity indices - were not capable of assessing the validity of every component of the interview. Notably, although the life stages were deliberately anchored to major events to facilitate recall, the level with which memory biases acted on informants' recall cannot be judged; and no comparable data on children's previous behaviour were available for validity assessment. A related limitation was the necessity to address widely spaced developmental stages to reduce demands on memory, which limited the precision of the present findings and led to the requirement for the indirect way correlational analyses were used to address the hypothesis with respect to rigidity during primary school. Furthermore, the retrospective nature of the interview meant that ratings based on duration and intensity of challenging behavioural responses - which have demonstrated validity for current behaviour measurement (Tunnicliffe et al., 2014) - would have been inappropriate due to unrealistic memory demands. However, since no existing measure was available that would have allowed examination of rigidity in routines and resistance to change over the course of children's development, these limitations could not be avoided.

The fact that the present participants included a majority still in primary school also represents a limitation because full analyses of subsequent life stages was not possible. However, the life stages that comprise the present primary analyses are also likely to have been more easily recalled by the informants of younger participants, so this could also represent a strength. Finally, the present sample size was small, which represents a limit to the generalisability of the findings and meant that there was insufficient power for even large sub-group differences in open ended data to be deemed statistically significant. However, PWS is a rare disorder and research based on similarly sized or smaller samples has been important in advancing the field (Woodcock et al., 2011; Tunnicliffe et al., 2014).

Despite these limitations, the present study represents a first critical step in the systematic examination of natural exposure to rigidity versus flexibility in routines over the life course and its relationship with the development of resistance to change. The present findings provide strong support for future longitudinal studies, and critically, a starting point for such work, which we hope will encourage its conduct.

\section{Acknowledgements}

The work was supported by the Prader-Willi Syndrome Association UK - with particular thanks to Jackie Waters - and the Prader-Willi Syndrome Association Ireland with particular thanks to Marguerite Hughes - the Foundation for Prader-Willi Research USA and the Foundation for Prader-Willi Research Canada in terms of crucial assistance with recruitment. The work would not been possible without the support of the participants with PWS and their caregivers who acted as respondents. 


\section{References}

Barker, J. E., Semenov, A. D., Michaelson, L., Provan, L. S., Snyder, H. R., \& Munakata, Y. (2014). Less-structured time in children's daily lives predicts self-directed executive functioning. Frontiers in psychology, 5, 593. doi: 10.3389/fpsyg.2014.00593.

Barker, J. E., \& Munakata, Y. (2015). Developing Self-Directed Executive Functioning: Recent Findings and Future Directions. Mind Brain and Education, 9(2), 92-99. doi:10.1111/mbe.12071

Best, J. R., Miller, P. H., \& Jones, L. L. (2009). Executive functions after age 5: Changes and correlates. Developmental Review, 29, 180-200. doi: 10.1016/j.dr.2009.05.002.

Boer, H., Holland, A., Whittington, J., Butler, J., Webb, T., \& Clarke, D. (2002). Psychotic illness in people with Prader-Willi syndrome due to chromosome 15 maternal uniparental disomy. The Lancet, 359(9301), 135-136. doi: 10.1016/s0140-6736(02)07340-3.

Bull, L. E., Oliver, C., Callaghan, E., \& Woodcock, K. A. (2015). Increased exposure to rigid routines can lead to increased challenging behavior following changes to those routines. Journal of autism and developmental disorders, 45(6), 1569-1578. doi: 10.1007/s10803-014-2308-2.

Bull, L. E., Oliver, C. \& Woodcock, K. A. (2016). Signalling changes to individuals who show resistance to change can reduce challenging behaviour. Journal of Behavioral Therapy and Experimental Psychiatry (available online from 22nd June 2016). doi: 10.1016/j.jbtep.2016.06.006

Cassidy, S. B. (1997). Prader-Willi syndrome. Journal of Medical Genetics, 34(11), 917-923. doi: 10.1136/jmg.34.11.917.

Clark, L. A., \& Watson, D. (1995). Constructing validity: Basic issues in objective scale development. Psychological assessment, 7(3), 309-319. doi: 10.1037/1040-3590.7.3.309.

Chevalère, J., Postal, V., Jauregui, J., Copet, P., Laurier, V., \& Thuilleaux, D. (2013). Assessment of Executive Functions in Prader-Willi Syndrome and Relationship with Intellectual Level. Journal of Applied Research in Intellectual Disabilities, 26(4), 309-318. doi: $10.1111 /$ jar.12044.

Cohen, J. \& Cohen, P. (1983). Applied multiple regression and correlational analyses for the behavioral sciences: Second edition, Hillsdale, New Jersey: Lawrence Erlbaum Associates.

Cole, M. W., Reynolds, J. R., Power, J. D., Repovs, G., Anticevic, A., \& Braver, T. S. (2013). Multitask connectivity reveals flexible hubs for adaptive task control. Nature Neuroscience, 16(9), 1348-U1247. doi:10.1038/nn.3470

Collette, F., Van der Linden, M., Laureys, S., Delfiore, G., Degueldre, C., Luxen, A., \& Salmon, E. (2005). Exploring the unity and diversity of the neural substrates of executive functioning. Human Brain Mapping, 25(4), 409-423. doi:10.1002/hbm.20118

Copet, P., Jauregi, J., Laurier, V., Ehlinger, V., Arnaud, C., Cobo, A. M., . . Thuilleaux, D. (2010). Cognitive profile in a large french cohort of adults with Prader-Willi syndrome: differences between genotypes. Journal of Intellectual Disability Research, 54, 204-215. doi:10.1111/j.1365-2788.2010.01251.x

Evans D. W. \& Gray F. L. (2000) Compulsive-like behavior in individuals with Down syndrome: its relation to mental age level, adaptive and maladaptive behavior. Child Development 71, 288-300. doi: 1111/1467-8624.00144

Evans, D.W., Leckman, J. F., Carter, A., Reznick, J. S., Henshaw, D., King, R. A., Pauls, D. (1997). Ritual, habit and perfectionism: The prevalence and development of compulsive-like 
behaviour in normal young children. Child Development, 68, 1, 58-68. doi: 10.1111/j.14678624.1997.tb01921.x.

De Los Reyes, A. (2011). Introduction to the special section: More than measurement error:

Discovering meaning behind informant discrepancies in clinical assessments of children and adolescents. Journal of Clinical Child \& Adolescent Psychology, 40(1), 1-9. doi: 10.1080/15374416.2011.53405.

Diamond, A., \& Lee, K. (2011). Interventions shown to aid executive function development in children 4 to 12 years old. Science, 333(6045), 959-964. doi:10.1126/science.1204529.

Dykens, E. M. (1995). Measuring behavioral phenotypes: Provocations from the "new genetics." American Journal of Mental Retardation, 99, 522-532. Retrieved from http://psycnet.apa.org/psycinfo/1995-29741-001.

Festen, D. A. M., Wevers, M., Lindgren, A. C., Böhm, B., Otten, B. J., Wit, J. M., Duivenvoorden, H., J. \& Hokken-Koelega, A. C. S. (2008). Mental and motor development before and during growth hormone treatment in infants and toddlers with Prader-Willi syndrome. Clinical endocrinology, 68(6), 919-925. doi: 10.1111/j.1365-2265.2007.03126.x

Fritz, C. O., Morris, P. E., \& Richler, J. J. (2012). Effect size estimates: current use, calculations, and interpretation. Journal of Experimental Psychology: General, 141(1), 2-18. doi: 10.1037/a0024338.

Goldstone, A. P., Holland, A. J., Hauffa, B. P., Hokken-Koelega, A. C., \& Tauber, M. (2008). Recommendations for the diagnosis and management of Prader-Willi syndrome. The Journal of Clinical Endocrinology \& Metabolism,93(11), 4183-4197. doi: 10.1210/jc.2008-0649.

Garon, N., Bryson, S. E., \& Smith, I. M. (2008). Executive function in preschoolers: A review using an integrative framework. Psychological bulletin,134(1), 31-60. doi: 10.1037/0033-2909.134.1.31.

Greaves, N., Prince, E., Evans, D. W., \& Charman, T. (2006). Repetitive and Ritualistic behaviour in children with Prader-Willi syndrome and children with autism. Journal of Intellectual Disability Research, 50(2), 92-100. doi: 10.1111/j.13652788.205.00726.x.

Green, V. A., Sigafoos, J., Pituch, K. A., Itchon, J., O'Reilly, M. \& Lancioni, G. E. (2006) Assessing Behavioral Flexibility in Individuals With Developmental Disabilities. Focus on Autism and Other Developmental Disabilities, 21(4), 230-236. doi: 10.1177/10883576060210040401

Hallgren, K. A. (2012). Computing inter-rater reliability for observational data: an overview and tutorial. Tutorials in quantitative methods for psychology, 8(1), 23-34.

Retrieved from http://www.ncbi.nlm.nih.gov/pmc/articles/PMC3402032/.

Hastings, R. P. (2002). Parental stress and behaviour problems of children with developmental disability. Journal of Intellectual and Developmental Disability,27(3), 149160. doi: $10.1080 / 1366825021000008657$.

Holland, A. J., Whittington, J. E., Butler, J., Webb, T., Boer, H., \& Clarke, D. (2003). Behavioural phenotypes associated with specific genetic disorders: evidence from a population-based study of people with Prader-Willi syndrome. Psychological Medicine, 33(01), 141-153. doi: 10.1017/S0033291702006736.

Holm, V. A., Cassidy, S. B., Butler, M. G., Hanchett, J. M., Greenswag, L. R., Whitman, B.Y., \& Greenberg, F. (1993). Prader-Willi syndrome: consensus diagnostic criteria. Pediatrics, 91(2), 398-402. Retrieved from http://pediatrics.aappublications.org/content/91/2/398.short.

Hutchison, M., Pei, J., Leung, W. S. W., Mackenzie, M., Hicks, M. D., Thurm, A. 
E., Hann, J.,C., \& Haqq, A. M. (2015). Parental Ratings of Children and Adolescents With PraderWilli Syndrome on the Behavior Rating Inventory of Executive Function (BRIEF). Journal of Mental Health Research in Intellectual Disabilities, 8(2), 55-71. doi: 10.1080/19315864.2015.1017893.

Jauregi, J., Arias, C., Vegas, O., Alen, F., Martinez, S., Copet, P., \& Thuilleaux, D. (2007). A neuropsychological assessment of frontal cognitive functions in Prader-Willi syndrome. Journal of Intellectual Disability Research,51(5), 350-365. doi: 10.1111/j.13652788.2006.00883.x.

Karbach, J., \& Kray, J. (2009). How useful is executive control training? Age differences in near and far transfer of task-switching training. Developmental science, 12(6), 978-990. doi: 10.1111j.1467-7687.2009.00846.x.

Karbach, J., \& Unger, K. (2014). Executive control training from middle childhood to adolescence. Frontiers in Psychology, 5, 14. doi:10.3389/fpsyg.2014.00390

Kharitonova, M., Chien, S., Colunga, E., \& Munakata, Y. (2009). More than a matter of getting 'unstuck': flexible thinkers use more abstract representations than perseverators. Developmental Science, 12(4), 662-669. doi:10.1111/j.1467-7687.2008.00799.x

Kharitonova, M., \& Munakata, Y. (2011). The role of representations in executive function: investigating a developmental link between flexibility and abstraction. Frontiers in Psychology, 2, 12. doi:10.3389/fpsyg.2011.00347

Kline, P. (2013). Handbook of psychological testing. Routledge.

Leekam, S. R., Prior, M. R., \& Uljarevic, M. (2011). Restricted and Repetitive Behaviors in Autism Spectrum Disorders: A Review of Research in the Last Decade. Psychological Bulletin, 137(4), 562-593. doi:10.1037/a0023341

Leekam, S., Tandos, J., McConachie, H., Meins, E., Parkinson, K., Wright, C.,

Turner, M., Arnott, B., Vitronini, L. \& Le Couteur, A L. (2007). Repetitive behaviours in typically developing 2-year-olds. Journal of Child Psychology and Psychiatry, 48(11), 1131-1138. doi: 10.1111/j.1469-7610.2007.01778.x.

Manning, K. E., McAllister, C. J., Ring, H. A., Finer, N., Kelly, C. L., Sylvester, K. P., . . Holland, A. J. (2016). Novel insights into maladaptive behaviours in Prader-Willi syndrome: serendipitous findings from an open trial of vagus nerve stimulation. Journal of Intellectual Disability Research, 60(2), 149-155. doi:10.1111/jir.12203

McHugh, M. L. (2013). The Chi-square test of independence. Biochemia medica, 23(2), 143-149. doi: 10.11613/BM.2013.018.

McHugh, M. L. (2012). Interrater reliability: the kappa statistic. Biochemia medica, 22(3), 276-282.

Mesibov, G. B., \& Shea, V. (2010). The TEACCH Program in the Era of Evidence-Based Practice. Journal of Autism and Developmental Disorders, 40(5), 570-579. doi: 10.1007/s10803-0090901-6.

Miller, J. L., Lynn, C. H., Shuster, J., \& Driscoll, D. J. (2013). A reduced-energy intake, well-balanced diet improves weight control in children with Prader-Willi syndrome. Journal of Human Nutrition and Dietetics, 26(1), 2-9. doi:10.1111/j.1365-277X.2012.01275.x

Miller, H. L., Ragozzino, M. E., Cook, E. H., Sweeney, J. A., \& Mosconi, M. W. (2015). Cognitive Set Shifting Deficits and Their Relationship to Repetitive Behaviors in Autism Spectrum Disorder. Journal of Autism and Developmental Disorders, 45(3), 805-815. doi:10.1007/s10803-014-2244-1

Monsell, S. (2003). Task switching. Trends in cognitive sciences, 7(3), 134-140. doi:10.1016/S1364-6613(03)00028-7. 
Moss, J., Oliver, C., Arron, K., Burbidge, C., \& Berg, K. (2009). The prevalence and phenomenology of repetitive behavior in genetic syndromes. J Autism Dev Disord, 39(4), 572-588.

Moss, J. \& Oliver, C. (2008). The Repetitive Behaviour Questionnaire. Manual for administration and scorer interpretation. University of Birmingham, UK.

Oliver, C., Woodcock, K. A., \& Humphreys, G. W. (2009). The Relationship between Components of the Behavioral Phenotype in Prader-Willi Syndrome. Journal of Applied Research in Intellectual Disabilities, 22(4), 403-407. doi: 10.1111/j.14683148.2008.00475.x.

Ozonoff, S., \& Strayer, D. L. (2001). Further evidence of intact working memory in autism. Journal of autism and developmental disorders, 31(3), 257-263. doi: 10.1023/A:1010794902139

Salkind, N. J. (Ed.). (2010). Encyclopedia of research design (Vol. 1). Sage.

Shivers, C. M., Leonczyk, C. L., \& Dykens, E. M. (2016). Life Satisfaction Among Mothers of Individuals with Prader-Willi Syndrome. Journal of Autism and Developmental Disorders, 46(6), 2126-2137. doi:10.1007/s10803-016-2741-5

Tunnicliffe, P., Woodcock, K., Bull, L., Oliver, C., \& Penhallow, J. (2014). Temper outbursts in Prader-Willi syndrome: causes, behavioral and emotional sequence and responses by carers. Journal of Intellectual Disability Research, 58(2), 134-150. doi: 10.1111/jir.12010.

Tvrdik, T., Mason, D., Dent, K. M., Thornton, L., Viskochil, D. H., \& Stevenson, D. A. (2015). Stress and coping in parents of children with Prader-Willi syndrome: Assessment of the impact of a structured plan of care. American Journal of Medical Genetics Part A, 167(5), 974-982. doi: 10.1002/ajmy.a.36971.

Uddin, L. Q., Supekar, K., Lynch, C. J., Cheng, K. M., Odriozola, P., Barth, M. E., ... Menon, V. (2015). Brain State Differentiation and Behavioral Inflexibility in Autism. Cerebral Cortex, 25(12), 4740-4747. doi:10.1093/cercor/bhu161

Van Eylen, L., Boets, B., Steyaert, J., Evers, K., Wagemans, J., \& Noens, I. (2011). Cognitive flexibility in autism spectrum disorder: Explaining the inconsistencies? Research in Autism Spectrum Disorders, 5(4), 1390-1401. doi:10.1016/j.rasd.2011.01.025

Viera, A. J., \& Garrett, J. M. (2005). Understanding inter-observer agreement: the kappa statistic. Fam Med, 37(5), 360-363. Retrieved from http://www1.cs.columbia.edu/ julia/courses/CS6998/Interrater_agreement.Kappa_statistic .pdf

Whittington, J. E., Holland, A. J., Webb, T., Butler, J., Clarke, D., \& Boer, H. (2001). Population prevalence and estimated birth incidence and mortality rate for people with Prader-Willi syndrome in one UK Health Region. Journal of Medical Genetics, 38(11), 792-798. doi: 10.1136/jmg.38.11.792.

Whittington, J., Holland, A., Webb, T., Butler, J., Clarke, D., \& Boer, H. (2004). Cognitive abilities and genotype in a population-based sample of people with Prader-Willi syndrome. Journal of Intellectual Disability Research, 48, 172-187. doi:10.1111/j.1365-2788.2004.00556.x

Wigren, M., \& Hansen, S. (2003). Rituals and compulsivity in Prader-Willi syndrome: profile and stability. Journal of Intellectual Disability Research, 47(6), 428-438. doi: 10.1046/j.1365-2785.2003.00515.x.

Woodcock, K., Oliver, C., \& Humphreys, G., W. (2009a). Associations between repetitive questioning, resistance to change, temper outbursts and anxiety in Prader-Willi and Fragile-X syndromes. Journal of Intellectual Disability Research, 53(3), 265-278. doi: 0.1111/j.1365-2788.2008.01122.x 
Woodcock, K. A., Oliver, C., \& Humphreys, G. W. (2009b). Task-switching deficits and repetitive behaviour in genetic neurodevelopmental disorders: data from children with Prader-Willi syndrome chromosome 15 q11-q13 deletion and boys with Fragile $X$ syndrome. Cognitive Neuropsychology, 26(2), 172-194. doi: 10.1080/0264329080268592.

Woodcock, K. A., Oliver, C., \& Humphreys, G. W. (2009c). A specific pathway can be identified between genetic characteristics and behaviour profiles in Prader-Willi syndrome via cognitive, environmental and physiological mechanisms. Journal of Intellectual Disability Research, 53(6), 493-500. doi: 10.1111/j.1365-2788.2009.01167.x

Woodcock, K. A., Oliver, C., \& Humphreys, G. W. (2011). The relationship between specific cognitive impairment and behaviour in Prader-Willi syndrome. Journal of Intellectual Disability Research, 55(2), 152-171. doi: 10.1111/j.1365-2788.2010.01368.x 
Table 1 Summary of questions from interview schedule pertinent to the primary research question and explanation of the rating scales where relevant

\section{Leading open ended questions}

Did you receive any advice about how to approach routines/structures after [person] was diagnosed?

Did your approach to routines/structures change as [person] was growing up?

Did [person] like to have routines/structures while they were growing up?

Dichotomous choice questions (yes/no) on each life stage (1. currently; 2. before school; 3. during Primary school; 4. during Secondary school; 5. after school

(1) Does/did [person] have a preference for predictability and structure in routines?

(2) Does/did [person] become upset following changes in routine, planned activities or what they were expecting?

\section{Open ended question on each life stage}

(3) Thinking about [person's] typical response to change now/at this time, can you describe [person's] behaviours?

\begin{tabular}{lll}
\hline Rating questions on all life stages & Rated as 1 & Rated as 5 \\
\hline $\begin{array}{l}\text { (4) Length of person's response to } \\
\text { change compared to other life stages }\end{array}$ & $\begin{array}{l}\text { Much shorter than more } \\
\text { recently }\end{array}$ & $\begin{array}{l}\text { Much longer than more } \\
\text { recently }\end{array}$ \\
\hline $\begin{array}{l}\text { (5b) Person's response to change } \\
\text { compared to other life stages }\end{array}$ & $\begin{array}{l}\text { Much less difficult than } \\
\text { more recently }\end{array}$ & $\begin{array}{l}\text { Much more difficult than } \\
\text { more recently }\end{array}$ \\
\hline $\begin{array}{l}\text { (6) Person's rigidity in routines for each } \\
\text { of: morning, mealtimes, bedtime, } \\
\text { leisure/school/work, other times }\end{array}$ & $\begin{array}{l}\text { Very rarely has/had the } \\
\text { same structure and routine }\end{array}$ & $\begin{array}{l}\text { Always has/had the same } \\
\text { structure and routine }\end{array}$ \\
\hline $\begin{array}{l}\text { (7) Person's rigidity in routines } \\
\text { compared to other life stages for each } \\
\text { of: morning, mealtimes, bedtime, } \\
\text { leisure/school/work, other times }\end{array}$ & $\begin{array}{l}\text { A lot less than more } \\
\text { recently }\end{array}$ & $\begin{array}{l}\text { A lot more than more } \\
\text { recently }\end{array}$ \\
\hline $\begin{array}{l}\text { Additions/differences for current life } \\
\text { stage (first set of questions } \\
\text { administered) }\end{array}$ & Rated as 1 & Rated as 5 \\
\hline $\begin{array}{l}\text { (4) (Difference in wording and rating) } \\
\text {..person's typical response... }\end{array}$ & Much shorter than before & Much longer than before \\
\hline $\begin{array}{l}\text { (5a) (Additional question) Person's } \\
\text { response to change }\end{array}$ & Very easy to deal with & $\begin{array}{l}\text { Very difficult to deal with } \\
\text { and causes destress to you } \\
\text { and others }\end{array}$ \\
\hline $\begin{array}{l}\text { (5b) (Difference in rating) } \\
\text { A }\end{array}$ & A lot less than before & $\begin{array}{l}\text { A lot more than more } \\
\text { before }\end{array}$ \\
\hline
\end{tabular}


Table 2 Operational definitions of codes identified in descriptive data from open ended questions

\section{Code name \\ Operational Definitions}

Code 1: Parents deliberately changing routines.
Parents deliberately 'mixing' things up, 'throwing' changes at, surprising their child to stop obsessive compulsive behaviours, rituals, regimented thinking, or to give their child practice at change.

Code 2: Child reacting negatively to change.

Parents describing child as anxious, upset, cross, angry, crying, shouting, screaming following change to routines, plans, or expectations.
Code 3: Routines benefiting a child's behaviour.

Parents reporting a positive response to routine, i.e. less behavioural problems, feeling more secure, preventing meltdowns.

Code 4: Rigid routines being detrimental to a child's behaviour.

Rigid routine leading to an increase in regimented thinking and/or challenging behaviour.

Parents report that response to change is dependent on level of importance placed on activity/expectation, i.e. if the activity is something the child has been very excited about, the response to the plan change will be more challenging than if the child was not interested.

There was more need for routines when their child was a baby and/or a toddler.

Code 6: More need for routines
babyhood and toddlerhood.

Parents reporting that they are not a

Code 7: Parents reporting not routine type family, like to do lots of instigating routines. different things, and/or do not have much of a routine.

Code 8: Child instigating some degree Parent reporting child has a preference of flexibility. for novelty/gets bored with the same routines/ wants to try new things. 
Table 3 Inter-informant percentage agreement

\begin{tabular}{llll}
\hline Type of question & Pair 1 & Pair 2 & Mean \\
\hline Response to change rating & 100.0 & 60.0 & 80.0 \\
\hline Routine level rating & 66.7 & 86.7 & 76.7 \\
\hline Comparative routine level rating & 70.0 & 70.0 & 70.0 \\
\hline
\end{tabular}


Table 4 Percentage of informants who reported each interview code in high and low resistance to change groups. The direction of the group difference is described, and phi statistic and odds ratios describe the size of the difference between groups (calculated based on the group on the left, compared to the group on the right of the expression in the Direction column).

\begin{tabular}{|c|c|c|c|c|}
\hline \multirow[t]{2}{*}{ Code } & \multicolumn{2}{|c|}{$\begin{array}{l}\text { Percentage of informants } \\
\text { who reported each } \\
\text { interview code }\end{array}$} & \multicolumn{2}{|c|}{ Difference } \\
\hline & $\begin{array}{l}\text { High current } \\
\text { resistance } \\
\text { to change }\end{array}$ & $\begin{array}{l}\text { Low current } \\
\text { resistance } \\
\text { to change }\end{array}$ & Direction & $\begin{array}{l}\text { Phi \& odds } \\
\text { ratio (OR) }\end{array}$ \\
\hline $\begin{array}{l}\text { Code 1: Parents deliberately } \\
\text { changing routines }\end{array}$ & 33.3 & 75 & Low $>$ High & $\begin{array}{c}\Phi=.41 \\
O R=6.0\end{array}$ \\
\hline $\begin{array}{l}\text { Code } 7 \text { : Parents reporting not } \\
\text { instigating routines }\end{array}$ & 33.3 & 75 & Low $>$ High & $\begin{array}{l}\Phi=.41 \\
O R=6.0\end{array}$ \\
\hline $\begin{array}{l}\text { Code 8: Child instigating some } \\
\text { degree of flexibility }\end{array}$ & 33.3 & 75 & Low $>$ High & $\begin{array}{l}\Phi=.41 \\
O R=6.0\end{array}$ \\
\hline $\begin{array}{l}\text { Code } 2 \text { : Child reacting negatively } \\
\text { to change }\end{array}$ & 100 & 75 & High $<>$ Low & N/A ${ }^{\dagger}$ \\
\hline $\begin{array}{l}\text { Code 4: Rigid routines being } \\
\text { detrimental to a child's } \\
\text { behaviour }\end{array}$ & 50 & 50 & High $<>$ Low & N/A ${ }^{+}$ \\
\hline $\begin{array}{l}\text { Code } 6 \text { : More need for routines } \\
\text { in babyhood and toddlerhood }\end{array}$ & 33.3 & 50 & High $<>$ Low & $\mathrm{N} / \mathrm{A}^{+}$ \\
\hline $\begin{array}{l}\text { Code 5: Level of response to } \\
\text { change being influenced by } \\
\text { activity or level of expectation }\end{array}$ & 66.6 & 50 & High $<>$ Low & $\begin{array}{l}\Phi=.17 \\
O R=2.0\end{array}$ \\
\hline $\begin{array}{l}\text { Code 3: Routines benefiting } \\
\text { their child's behaviour }\end{array}$ & 83.3 & 25 & High > Low & $\begin{array}{c}\Phi=.58 \\
O R=15.0\end{array}$ \\
\hline
\end{tabular}

† Measures of effect size not computed since frequency of reporting differed by a maximum of one person 